\title{
EXERCÍCIOS PARA PENSAR O JOGO DE EPISTEMES
}

DOI: 105902/0102830820164

Ensaio Convidado.

\section{Silvino Santin}

s26santin@gmail.com

Universidade Federal de Santa Maria

RESUMO: Trata-se de um exercício no pensamento filosófico sobre o jogo de epistemes na construção de conhecimentos na e para a Educação Física. O objetivo principal, no entanto, é identificar possíveis motivações, interesses e necessidades que levaram os homens a desenvolver e organizar a capacidade de pensar e assim, no caso, construir conhecimentos. Para a Educação Física analisa-se assim, "caminhos e descaminhos que tensionam epistemes".

Palavras-chave: Jogo. Episteme. Educação Física. 


\section{Introdução}

Não sei se o título é suficientemente acadêmico e científico. Talvez se trate apenas de uma aula inspirada na maiêutica socrática ou numa jornada hermenêutica heideggeriana, inspiradas no pensar originário. Tudo começa pela escuta das palavras, aquelas que anunciam o presente tema. Sim, as palavras falam desde tempos imemoriáveis.

\section{Pensar}

Para falar sobre pensar, sedo que todos pensam, é suficiente prestar atenção às seguintes expressões: "vou pensar", "fiz sem pensar", estou pensando". Ou responder a essas perguntas: "Como faço para pensar? O que acontece quando penso? Por fim que diz pensar?

Os filósofos sempre admitiram que o pensar pertence à natureza humana. Blaise Pascal (1623-1662) afirmou: "O homem é um caniço, mas é um caniço pensante". Razão pela qual o pensar constitui-se na mais alta grandeza do homem. Os neurobiólogos, como Antônio Damásio, afirmam que o pensar é uma atividade constante do cérebro humano. Resta saber se os humanos querem pensar. Se escutarmos a fala de Soren Kierkegaard (1813-1855), parece que não há muita disposição: "O povo pede o poder da palavra para compensar o poder de livre pensar do qual ele foge."1

O desafio, portanto, está em saber o que se entende pelo ato de pensar. Neste sentido, provavelmente, Martin Heidegger foi o pensador que mais se dedicou a decifrar o pensar, Ele dedicou um curso sobre o tema com duração de dois semestres (inverno -1951-1952- e verão 1952). A conclusão, se é que é possível chamar de conclusão, foi a seguinte: Pelo fato de que nos engajamos neste aprendizado, confessamos que nós pensamos". ${ }^{2}$

\footnotetext{
${ }^{1}$ Kierkegaard, Soren. Kirkeggar Vivant. Paris: Gallimard, 1966.
}

2 Heidegger, Martin. Idem, p. 21. 
Jogo

Por que falar em jogo de epistemes? Muito simples, porque o pensar e o lúdico (brincar) possuem a mesma dinâmica. Nenhum está determinado a priori. Acontecem num cenário da liberdade, da criatividade e da originalidade do imaginário. Pensar e brincar não tem começo, não tem fim, porque recomeçam sempre e continuamente. É suficiente que um pensador ou um brincador se disponham a pensar ou a brincar. Não há preocupação em continuar o pensamento ou o brinquedo de ontem. Tudo começa como sendo original.

As razões podem ser questionadas, mas se for aceito que o lúdico é a raiz do humano, segundo Friedrich Schiller (1759-1805): "o homem joga somente quando é homem no sentido pleno da palavra, e somente é homem pleno quando joga. O jogo (lúdico) é a ausência de regras ou conceitos numa verdadeira liberdade humana" ${ }^{3}$. E a capacidade de pensar é a identidade específica do ser humano, na afirmação de Heidegger: "O homem se chama, portanto, aquele que pode pensar"4.

O brincar e o pensar, entretanto, não se fecham na sua originalidade lúdica e imaginária, pressionados pelo processo de desenvolvimento da espécie humana passam a assumir determinadas organizações para atender às necessidades da vida e da sobrevivência da humanidade, particularmente, pelas exigências da ordem sociocultural. O Brinquedo se transforma em jogo e trabalho. O pensamento se torna raciocínio (ratio), isto é, capacidade de criar e articular pensares para chegar ao conhecimento e construir ciências visando orientar a vida pessoal, as relações com os outros e com o mundo. Surgem as condições para o fenômeno da episteme e, sucessivamente, das tensões de epistemes.

\footnotetext{
${ }^{3}$ Schiller Friedrich (1759-1805). Uber die Asthetische Erziehung des Menschen.- Einer Reihe Von Briefen. Tradução: Sobre a Educação Estética do homem. Numa série de cartas.. São Paulo: Iluminuras. 1990. P.84.

${ }^{4}$ Heidegger, M. Opus cit. p 21.
} 


\section{Episteme}

Epistema é uma palavra grega que deve ser escutada no universo do pensar grego. Geralmente é traduzida como ciência. Essa tradução é mais latina do que grega. Segundo Heidegger, episteme significa "colocar-se e estar diante de algo de maneira que nesse colocar-se e estar-diante-de algo se mostre para nos"s.

\section{Estratégias para descrever e interpretar o Jogo de epistemes.}

Pela maneira como, originalmente, o pensar humano foi sendo regulamentado em função da sua expressão, da sua comunicação e da sua compreensão, o falar e o pensar se constituíram numa coisa só. Heidegger afirmou que "o pensamento jamais se limita a utilizar a língua, mas pensar é o falar inicial”ø. Entre o dizer e o dito não havia distância. Somente com o avanço da linguagem conceitual e das lógicas surgiram as teorias dualistas. "O mapa não é o território, e o nome não é a coisa"7. Mas esta seria uma longa digressão. Neste momento, quero sublinhar que, se o pensamento humano evoluiu pressionado pelo homem para conhecer a si mesmo e conhecer o mundo, foi preciso estabelecer alguns requisitos fundamentais. Neste mesmo sentido, para realizar a tarefa que me propus preciso recorrer a alguns pressupostos.

\section{Pressupostos da descrição Filósofos da ciência}

Um número crescente dos chamados filósofos das ciências, muitos com formação nas ciências experimentais, dedicam-se ao estudo das circunstâncias que levaram os estudiosos, em geral, a estabelecer métodos e critérios de cientificidade, relegando outros saberes à condição de não-saberes.

\footnotetext{
${ }^{5}$ Heidegger, M. Heráclito. Rio de Janeiro, Relume, 1998, p. 233.

${ }^{6}$ Heidegger, M. Op. cit. p. 139.

${ }^{7}$ Bateson, Gregory. Natureza e Espírito - Uma unidade necessária. Lisboa: Dom Quixote, 1987. P.35.
} 
Entre outros estudiosos da questão, vou citar alguns pelo simples critério de que conheço suas obras. Começo por Bruno Latour e Steve Woolgar, autores da obra A Vida de Laboratório - A produção dos fatos científicos. Penso que o subtítulo diz tudo. Não exige comentários. O fato (objeto) levado ao laboratório, depois de passar pelos testes, acaba sendo definido como fato científico, quando, de fato, seria um artefato científico ${ }^{8}$.

A tese fundamental da minha descrição é a que foi formulada por Francisco Varela ao relacionar as ciências à ordem social. Para ser mais prático e compreensível vou transcrever a seguinte passagem de uma de suas obras: "Cada época da história da humanidade produz, pelas suas práticas sociais quotidianas e pela sua linguagem, uma estrutura imaginária. A ciência é parte integrante dessas práticas sociais, e as teorias científicas da natureza representam apenas uma dimensão dessa estrutura imaginária"9.

Gérard Fourez defende uma relação entre sociedade e ciência de maneira mais comprometedora. Para ele as ciências surgem vinculadas a um grupo. Portanto a ciência é uma produção cultural particular de uma civilização particular. No caso, "a ciência moderna, exemplarmente, liga-se à representação do mundo próprio da burguesia, que se sente exterior ao mundo, ao mesmo tempo que tenta explorá-lo e dominá-lo"10.

Thomas Kuhn, o teórico da prioridade dos paradigmas, sustenta uma tese muito próxima à Fourez, embora mais restrita em relação ao grupo social. Para ele, a cientificidade, atualmente, depende da comunidade científica. Científico é o que a Comunidade Científica confirma ${ }^{11}$. Basta lembrar a recusa das leis de Mendel (1822-1884) pela comunidade científica de seu tempo.

\footnotetext{
${ }^{8}$ Latour, Bruno e Woolgar, Steve. A Vida de Laboratório - A produção dos fatos científicos. Rio de Janeiro: Relume Dumará, 1997.

${ }^{9}$ Varela Francisco. Connaître - les sciences cognitives tendances et perspectives. Paris: Seuil, 1988. P. 9/10.

${ }^{10}$ Fourez, Gérard.. As Construções das Ciências - Introdulçao à Filosofia e à Ética das Ciências. São Paulo: UNESP, 1995. P. 191/2

${ }^{11}$ Kuhn, Thomas. A Estrutura das Revoluções Científicas. São Paulo; Ed. Perspectiva, 1987.
} 


\section{Motivações Epistêmicas}

O objeto, aqui isado, é o de identificar as possíveis motivações, interesses, necessidades que levaram os homens a desenvolver e organizar a capacidade de pensar.

Para operacionalizar esse projeto, o suporte vem de Eduard Berstein (18501932). ao propor que o filosofar pode ser compreendido a partir de dois tipos de pensar ou de interpretar o mundo, baseados em dois códigos distintos.

\subsection{Código restrito.}

O código restrito, num primeiro momento, descreve os objetos presentes como são vistos. O segundo momento, se caracteriza pelo debate entre pessoas que adotam os mesmos pressupostos sobre um determinado objeto.

\subsection{Código elaborado.}

O código elaborado coloca temas como a vida, a liberdade, a justiça, a morte, etc. questionando seus princípios fundamentais ${ }^{12}$.

\section{Motivações das construções das ciências}

Os historiadores e filósofos das ciências não apresentaram uma explicação única para demonstrar como o ser humano partiu de um determinado ponto de sua evolução biológica para alcançar o estágio da percepção simbólica até chegar à representação abstrata da realidade. O conceito, por exemplo, nada mais é que uma representação mental geral e abstrata de um objeto. O ponto em comum é o reconhecimento de que houve uma série de fatores que, uma vez conjugados, possibilitaram a construção organizada de saberes, até chegar, como afirma Heidegger, à identidade do homem a "ratio", que é raciocinar, criar e articular pensamentos (pensares).

${ }^{12}$ Berstein, Eduard. In Fourez, G. As construções das Ciências. Introdução à Filosofia e à Ética das Ciências. São Paulo: UNESP. 1995. 
A preocupação humana de conhecer, revelada na longa caminhada que começou com o reconhecimento dos objetos na presença até as estruturas metafísicas, é um fato comprovado. O desafio dos pesquisadores é estabelecer como aconteceu a sucessão das diversas etapas. Por exemplo, segundo a teoria de Teihard de Chardin, a passagem da esfera da matéria para a bioesfera, ou desta para a noosfera, foi definida como "Ponto Crítico"13, enquanto Fritjof Capra prefere falar em "Ponto de Mutação"14. Nenhum dos dois autores, no meu entender, explicam o fenômeno. Ao contrário, o "mistério", ou o "milagre" segundo Jacques Monod, tornaram-se mais evidentes. Milagre? Porque foi fruto do acaso e somente teria acontecido uma única vez ${ }^{15}$.

O caminho que eu julgo possível de percorrer é descrever os fatos consumados, isto é, quando a nova estrutura imaginária, referida por Varela, já está instalada na história do processo de criações de conhecimento.

\section{O encontro das estruturas imaginárias.}

A teoria das estruturas imaginárias, proposta por Varela, refere-se à atitude da humanidade de ordenar suas práticas sociais a partir de estruturas que se imagina correspondam à realidade. A constituição matemática e geométrica do universo, proposta por Galileu é um exemplo de explicação do universo. 0 criacionismo e o evolucionismo são duas estruturas imaginárias da explicação das origens do universo e do ser humano. De fato, essas estruturas correspondem a uma construção imaginária de épocas e culturas diversas. A história mostra com clareza a existência dessas estruturas na ordem social. A estrutura da sociedade medieval feudal não é a mesma da sociedade moderna capitalista. A estrutura familar diverge do Cristianismo para o Islamismo.

${ }^{13}$ Chardin, Teilhard de. O Fenômeno Humano. São Paulo: Cultrix, 1955.

${ }^{14}$ Capra Fritjof. O Ponto de Mutação. São Paulo: Cultrix, 1982.

${ }^{15}$ Monod, Jacques. O Acaso e a Necessidade. Petrópolis: Vozes, 1976. Para Monod o surgimento da vida foi possível graças a convergências de tantos fatores que poderia ser considerado um milagre. P. 154 e 163. 
A ciência, como disse Varela, faz parte dessas construções imaginárias. Chegou o momento para ir ao encontro destas estruturas imaginárias sob a ótica das relações entre o conhecimento e a ordem social.

\subsection{O imaginário do sagrado}

No instante primordial em que os seres humanos se defrontaram com a descoberta de que o mundo se oferecia numa percepção para além dos limites físicos e biológicos, começa a busca de uma resposta. O mundo se apresenta com outros significados ou o homem descobre que as coisas que o rodeiam podem significar algo que as ultrapassa. Era preciso encontrar um elemento que possibilitasse fazer essa nova leitura ou ter outra percepção.

Como isso aconteceu não foi suficientemente esclarecido pelos antropólogos. Para Cassirer esse é o momento em que se manifesta a capcidade de simbolizar, tanto que para ele, o ser humano é um ser simbolizador ${ }^{16}$. O que foi possível constatar é que os povos primitivos optaram pela idéia do sagrado ou da magia, isto é, o operar das forças invisíveis que regem o universo. Devia haver entidades superiores responsáveis pela ordem universal. Neste contexto foram criadas as narrativas míticas. Os mitos de origem desenharam a primeira estrutura "científica" do mundo e de tudo o que nele existe, neles estão insritos a origem, a realidade e o projeto de cada povo.

René Thom, numa enrevista, declarou: "Na verdade, a magia tem, no universo primitivo uma função de "inteligibilidade": é um sistema de pensamento que permite conceber os processos naturais e eventualmente fornecer os meios de agir sobre eles". E acrescenta: "A magia é o antepassado da ciência somente enquanto método de representação das forças físicas que permite a compreensão e mesmo a ação"17. Segundo ele, a ciência não elimina a magia tanto que todos os

\footnotetext{
${ }^{16}$ Cassirer, Ernest. Ls philosofie ddes formes symboliques. Paris: Les Eddition de Minuit, 1953.

${ }^{17}$ Thom, René. A aventura científica sob risco de heresia. In Pessis-Pastenak, Guitta. Do Caos à Inteligência Artificial. São Paulo: UNESP, 1991. P.30.
} 
instrumentos modernos, se ignorarmos suas leis de funcionamento, são portadores de magia.

Os mitos, narrativas teóricas do sagrado, foram suficentes durante milênios para fundamentar em toda a extensão a ordem individual e social de cada povo. O lugar do poder estava bem definido na manutenão das tradições ancestrais, especialmente na vigilância sobre o mito de origem, e no controle das forças espirituais para afastar os males, inclusive as doenças, e atrair as forças do bem. Os titulares desses poderes variavam conforme cada povo. O xamã concentrava o poder supremo por ser considerado aquele que mantinha um contato direto com os entes superiores espirituais, e o único legitimado para o exercício dos rituais. Também, chamado de mago, feiticeiro, curador, pajé, etc.

A história evolutiva da humanidade mostra que, num determinado momento, o sagrado esgotou suas possibilidades de enfrentar os novos desafios, em parte, devido às alterações do movimento das modificações no regime de vida dos povos e pela insatisfação com as crenças míticas. A situação era tão complexa que somente uma revolução radical resolveria. Era necessario não só uma modificação de paradigma, mas de referencial "teórico" para criar uma nova estrutura.

\subsection{0 imaginário lógico.}

Os precedentes do imaginário lógico, sob o ponto de vista geográfico, começaram a se desenhar há, aproximadamente, quatro milênios, quando na penísula balcânica, onde fica a Grécia Antiga, passou a abrigar vários povos de descendência indoeuropéia. Cada um tinha sua tradição mítica e suas crenças ancestrais. A harmonização dessas diversidades culturais exigia procurar outro referencial teórico de caráter não mítico. Tudo teria começado, quando no século IX antes da Era Cristã, os pensadores, classificados como pré-socráticos, buscaram a explicação das origens a partir de elementos do próprio universo. Fixaram quatro, terra, água, ar e fogo, como componentes originários da constituição de todos os entes do universo, celestes e terretres. Esse foi o primeiro passo da primeira revolução radical do pensar humano. 
O segundo passo começou com Sócrates ao propor que o homem devia conhecer a si mesmo, sintetizado na sua exortação: "conhece-te a ti mesmo". Essa frase tinha um alcance bem maior que o conhecimento de si mesmo. Ela inclui uma nova maneira de acessar a verdade e o conhecimento que já estão no interior de cada um. Platão continuou o projeto socrático. Aliás, Socrates nada escreveu. O que sabemos dele foi através dos diálogos de seu discípulo, Platão.

Platão estabeleceu que a natureza é o princípio fundante do conhecimento verdadeiro. Assim, a natureza define o que é cada um e seu comportamento. A natureza específica do ser humano é a psique, que lhe confere a capacidade de conhecer o mundo. Embora, segundo Platão, todos os seres vivos são dotados de psique, entretanto, a psíque dos seres humanos é superior à dos outros viventes. A psique humana é imortal. E mais, ela é, segundo Platão, de três tipos correspondentes à diferença de funções. A psíque racional, que reside na cabeça, tem como função a busca do conhecimento e do governo. Para psique irascível, que reside no peito, sua função é proteger e defender. A psique concupiscível, que reside no abdome, tem como função dedicar-se ao sistema produtivo e aos bens materiais.

Fica claro que a antropologia platônica define a ordem social em três classes, a dos trabalhadores, a dos defensores e a dos governantes. A cabeça é o lugar do saber e do poder. O peito é o lugar da força. $O$ abdome é lugar dos instintos.

Até hoje a cabeça é o símbolo do conhecimento, da razão e do poder. Há uma longa lista de referências à simbologia da cabeça como o órgão do equilíbrio, do controle, da chefia, etc. Ou expressões como: "usar a cabeça", "ter a cabeça no lugar", etc.

Na sequência, Aristóteles sistematizou, sem dúvida, a estrutura imaginária filosófica que, não só rompeu com o imaginário sagrado, mas estabeleceu as bases de futuras estruturas imaginárias a partir do raciocínio lógico e do princípio de causalidade como explicação de qualquer evento. 


\section{3. $O$ imaginário jurídico.}

O Império romano dominou politicamente a Grécia, reduzida a uma província. Entretanto, Roma acabou sucumbindo à cultura grega. Esta rara relação de consquistadores/consquitados, inspirou a expressão "o vencido venceu o vencedor". A força do raciocínio lógico grego tornou-se o instrumento fundamental para elaborar - Direito Romano, a solução encontrada para organizar a sociedade composta de imigrantes em busca de um lugar para viver, ou levados como escravos pelas guerras de conquista. Impunha-se uma nova estrutura capaz de determinar novas relações comportamentais e interpessoais. Essa tarefa foi chamada de legislação ou legislar por que a solução encontrada foi estabelecer leis que definissem os direitos e os deveres de todos e de cada um segundo seu lugar social: nobres, plebeus e escravos. A lei tornou-se o referencial "científico" da estrutura jurídica romana, que pode ser resumido pela palavra Jurisprudência.

Assim, a jursiprudência romana e a filosofia grega permaneceram como referência para futuras estruturas imaginárias.

\subsection{O imaginário teológico.}

Os primeiros séculos da era cristã continuaram marcados pelas correntes migratórias quando se consolida um processo de formação de Estados no formato de impérios, cujo chefe, o imperador, detinha um poder absoluto, aceito como de origem divina. Seja pela crença de uma nobreza divina, seja pela consagração de um ritual religioso.

É nesta época que acontece uma forte articulação entre a filosofia grega, a jusrisprudência romana e a doutrina cristã. Esta última assume o comando dessa articulação. A crença num Deus único vedadeiro encontra na mentalidade monárquica, o ambiente receptivo. A mensagem evangélica de igualdade dos homens, ainda que somente perante Deus não entre os homens, foi recebida com simpatia pelos menos favorecidos. Todos eram filhos de Deus. Por fim, a doutrina revelada bíblico-cristã encontrou o suporte teórico na filosofia grega. 
A verdade revelada e a verdade raciocinada formaram uma estrutura única. A verdade revelada estava escrita no livro sagrado, a Bíblia; a verdade raciocinada deveria emergir da interpretação do texto sagrado, observando os princípios da filosofia grega.

Surgia assim a estrutura imaginária vinculando deliberadamente o saber e o poder. O saber foi controlado pela Igreja sob a autoridade do Papa e graças às ordens religiosas, centros de estudos. Ao imperador pertencia o poder civíl ou leigo, ainda que precisasse prestar obediência ao poder religioso.

Era o tempo das heresias, das excomunhões, das condenações, das fogueiras. Era, também, o momento de buscar novos horizontes, um apelo ao imginário. Uma nova estrutura de conhecimento, mais uma vez, seria a abertura para outra mentalidade e uma nova ordem social.

\subsection{O imginário hermenêutico e matemático.}

Era fundamental abalar a suporte do poder absoluto que mantinha o controle sobre a fonte do saber, a Bíblia. O critério último de verdade estava no texto sagrado. Sua interpretação dependia do aval (nihil obstat) da autoridade eclesiástica. Era preciso romper com essa estrutura de poder. O caminho mais seguro foi pensar alternativas de produção de conhecimentos, superando as estruturas vigentes de cientificidade.

Martinho Lutero (1483-1546) foi o precursor desta nova revolução radical. O Movimento Luterano rebelou-se, entre outros fatos, contra o controle da interpretação da Biblia. A tese consistia em que "Todos os cristãos, como portadores do Esírito Santo, têm condições para interpretar a mensagem bíblica". A proposta, aparentemente, parece muito simples. De fato, não é. Dois fatores foram exigidos para romper com o sistema, tanto de criar possibilidades de conhecimentos, pela liberdade hermenêutica, tanto, e especialmente, por negar o monopólio do controle da hermenêutica. Não se pode esquecer que o texto sagrado era intocável. 
O movimento luterano, conhecido pelo nome de Reforma Protestante, abriu o caminho para uma nova cientificidade. Esse caminho foi inaugurado por Galileu Galilei (1564-1642), começando por substituir o livro de conhecimento. O universo seria o verdadeiro livro da ciência. A bíblia era o livro da doutrina religiosa. A escrita do universo não seria de palavras ou frases, mas de números e figuras geométricas. A matemática e a geometria seriam a linguagem para ler o universo. Ninguém desconhece as dificuldades enfrentadas por Galileu.

Ficou definida a nova cientificidade fundante da modernidade.

\subsection{O Imaginário racional.}

Uma vez colocado em questão o modelo autoritário sobre os métodos de chegar ao conhecimento, tornava-se necessário estabelecer as bases de sustentação do novo projeto de construção de conhecimentos. O universo, proclamado o novo livro de conhecimento, exigia um novo leitor. Entretanto este novo leitor que não mais tinha o acompanhamento divino, devia mostrar suas credenciais. Neste momento Descartes se apresenta com seu "cógito, ergo sum" (penso, portanto existo). A Razão seria a capacidade humana capaz de conhecer pela leitura da escrita do universo. Em sua obra, "Discurso sobre - Método", Descartes traça a metodologia pela qual a mente humana poderia alcançar o conhecimento verdadeiro. Essa metodologia tinha como princípio "partir do conhecido para chegar ao desconhecido". E o ponto de partida conhecido é o fato de pensar. E o fato de pensar é prerrogativa da Razão. Começava a era moderna.

Um dado importante sobre Descartes é sua formação matemática. As coordenadas cartesianas são uma comprovação. Outro aspecto que, também, não se pode esquecer é que os filósofos de Descartes até Husserl tinham em sua bagagem intelectual profundos estudos das matemáticas, transformadas em alfabeto e sintaxe para entender a linguagem do universo desde Galileu, e portadoras de raciocínio rigoroso. 
A Razão passa a ser o único critério do certo e do errado, do bem e do mal, do verdadeiro e do falso. Portanto, qualquer suposto conhecimento que não passasse por esse crivo não era portador do selo de verdade.

A Razão tornou-se a deusa Razão. Ela passou a comandar todas as ações humanas. Esse domínio da razão não é apenas sobre a ciência, mas sobre tudo. Atualmente a racionalidade é estendida aos sistemas de produção, ao setor administrativo, à economia, etc.

A importância dada ao operar da Razão pode ser medida pelos debates sobre o novo modelo de Universidade, desenvolvidos na Alemanha no final do século XVIII e início do século XIX. Kant escreveu, sobre o assunto, a obra "O conflito das Faculdades" (1798), onde propôs a seguinte organização. A universidade deveria ser formada por três faculdades superiores, a saber: a de Teologia para atender o bem eterno do homem; a de Direito para atender o bem social; a medicina para atender o bem temporal, a saúde. As três deveriam estar sob o controle do Estado. A quarta Faculdade, denominada por ele inferior, a de Filosofia, como só se ocupa do interesse da ciência e da verdade, deve gozar de liberdade plena ${ }^{18}$.

Até este momento a força da racionalidade se mantinha no circuito do desenvolvimento intelectual. O tema central girava em torno da legitimidade da razão para estabelecer os fundamentos do acesso correto ao conhecimento. As universidades mantinham as pesquisas no campo teórico, tendo a metafísica como o referencial último de toda ciência sob o controle de um grupo restrito de pessoas. Como afirmou Artur Gianotti: "A universidade é o lugar da elite. É uma elite. A universidade deve ser de elite. Porque os países precisam de elites" ${ }^{\prime 9}$.

${ }^{18}$ Trad. Francesa por Gobelin, Jean, Les Conflits des Facultés. Paris: Vrin, 1955, p. 13-17 e 27.

${ }^{19}$ Gianotti, J. Artur. Entrevista apud Silva, Juremir Machado da. O pensamento do fim do século. Porto Alegre: L\&PM, 1993. P. 


\subsection{O Imaginário industrial.}

A segunda metade do século XVIII e o início do século XIX foram o cenário de um movimento revolucionário, não bélico, mas de um conjunto de profundas e amplas transformações sociais. O seu nome é Revolução Industrial que, segundo alguns, foi seguida de outras revoluções industriais, segundo outros, teria apenas outras fases. A principal particularidade dessa revolução, apontada pelos analistas da história, teria sido a substituição do trabalho artesanal pelo assalariado e com o uso das máquinas.

O aspecto que vou sublinhar é o novo papel desempenhado pelo conhecimento ou pela ciência. As pesquisas científicas, aos poucos, se aproximaram das atividades humanas. Tornaram-se um instrumento de ampliação da força humana e de referência teórica e de inovação para o sistema produtivo. No primeiro caso, há uma considerável presença da técnica para o rendimento laboral; no segundo caso, a aplicação dos conhecimentos torna o sistema de produção mais eficiente, mais produtivo e mais rentável. As ciências passam a ter um papel fundamental para assegurar e manter o processo revolucionário industrial atualizado.

Resumidamente, fica claro que há um casamento entre ciência e sistema produtivo. A ciência passa a ser o único suporte legitimado e confiável para qualquer empreendimento racional. No primeiro momento esse casamento foi comandado pela ciência. Isto é, a ciência determinava o que e como as atividades produtivas deviam operar. No segundo momento, os papéis se invertem. O sistema produtivo, já dominado pelo interesse comercial, passa a determinar o que a ciência deve investigar. Os interesses industriais comerciais passam a determinar o que deve ser investigado. Quais áreas merecem investimentos para a pesquisa. Uma simples observação do cenário atual mostra o quanto as instituições financeiras impõem condições de financiamento para determinados setores das pesquisas científicas. As universidades não estão imunes destes humores. O próprio conhecimento foi transformado em mercadoria. É suficiente acompanhar a procura dos cursos acadêmicos para perceber a diferença entre os cursos profissionalizantes, entre eles os que oferecem maiores 
vantagens econômicas, e as licenciaturas que, na maior parte, conduzem ao magistério. Mesmo no sistema produtivo de bens, por exemplo, a agricultura sustentável ou orgânica fica num segundo plano, assim como a política do bem-estar social.

\subsection{O imaginário existencial.}

Até aqui o ser humano foi tratado, pelas ciências empíricas, como um objeto entre outros objetos físicos de pesquisa; pela filosofia, como um conceito universal abstrato. Com o desencanto da inviabilidade de transformar a filosofia em ciência rigorosa através da metafísica ${ }^{20}$, os filósofos, especialmente existencialistas, focaram o ser humano situado no tempo e no lugar, isto é, um ser-no-mundo. Inicialmente enquanto consciência de si e, na sequência, enquanto um ser corporal. "Sou corpo" é a expressão correta em lugar de "tenho corpo"21. Compreendendo a corporeidade como a totalidade do ser humano.

Esta nova mentalidade filosofante trouxe uma atmosfera revitalizante para as ciências humanas em geral. As neurociências ampliaram a valorização do ser humano como um sistema vivente auto-organizacional.

\subsection{O Imaginário Estético.}

Liberto das metafísicas e dos conceitos, o ser humano passa a ser compreendido pela sua constituição vital que se expressa na sua totalidade através do corpo. As dimensões corporais humanas, que a razão havia marginalizado ou excluído, encontram um espaço seguro no imaginário estético, isto é, o imaginário da sensibilidade. Surge um novo liame social, para além do sentido da polis grega, o sentido a partir de uma maneira de experimentar, com outros, alguma coisa. A esse fato, Maffesoli chama de Ética da Estética, onde assumem importância o imaginário, a paixão, a emoção, isto é, o afetivo da vida social22.

\footnotetext{
${ }^{20}$ Husserl, E. "A filosofia como ciência, como ciência série, rigorosa, e até apoditicamente rigorosa: este sonho acabou". La crise des sciences européennes et la phénoménologie transscendentale. P. 563.

${ }^{21}$ Merleau-Ponty, Maurice. Phénoménologie de la Perception. Parias: Gallimard, 1945. P.173

${ }^{22}$ Maffesoli, Michel. Comunicação e Pós-Modernidade. In Textos Comunicação e Pós-Modernidade. Salvador: UFB, 1985. P.
} 
A vida passa a ser o referencial primordial do imaginário estético. Não a vida em si, mas a vida manifesta em cada ser vivente. Sempre original. Porque o corpo é o primeiro indício de originalidade, que deixa de ser um conceito ou um objeto de laboratório todo esquadrinhado, para assumir uma fisionomia, um rosto. Como afirma Levinas: o outro é rosto. E o rosto tem significado sem contexto. Fala-se, em geral, do outro num contexto, é professor, é diretor, etc. O rosto é rosto. Ele é aquele que não se pode transformar em conteúdo. Portanto a relação com o rosto não é de saber, mas ético ${ }^{23}$.

\section{Perspectivas e caminhos}

Cheguei ao momento mais complexo e mais instigante da minha caminhada fenomenológico-hermenêutica, isto é, da descrição e interpretação. A descrição consistiu em percorrer o processo histórico de construções de estruturas de conhecimento pelo imaginário social. A interpretação focalizou a importância das motivações e o significado do poder nas construções de estruturas.

No meu planejamento deveria, agora, relacionar a produção ou, no meu entender, construção de conhecimentos referente à Educação Física. A tarefa, ainda que muito surpreendente e atrativa, seria muito extensa e cheia de digressões. Diante do tempo limitado, imposto pelas regras da programação, vou concentrar a atenção sobre alguns aspectos do momento atual da educação física.

É inegável que, atualmente, a Educação Física entrou num cenário acadêmico, individual, social, econômico e político que atrai atores das mais diferentes instituições em qualquer esfera da atividade humana. Não é fácil encontrar alguma ciência que não tenha alguma contribuição a dar para a educação física. Mas não é no mundo das ciências que pretendo investir esta última parte da minha apresentação. Prefiro acentuar as perspectivas de caminhos, não incluiria descaminhos, quase ilimitados, não só de epistemes, mas de desenvolvimento

${ }^{23}$ Levinas, Emanuel. Ética e Infinito. Lisboa: Edições 70. 1982. P.77-84 
humano. È esse último aspecto que será privilegiado. Para isso preciso trazer alguns dados indispensáveis para confirmar a responsabilidade da educação física na construção de uma sociedade humanizada.

Aponto três áreas da presença reconhecidamente prioritárias da atuação da Educação Física. No contexto das epistemes limito a minha abordagem a uma área não muito frequentada, ainda que, desde a filosofia grega, tenha sido uma questão pertinente e provocativa. Refiro-me à ética, hoje, acrescida pela Bioética.

\subsection{Educação Física, ação pedagógica.}

A educação física, como dizem as palavras, foi entendida quase exclusivamente como uma ação pedagógica, embora fosse uma pedagogia não centrada na corporeidade de cada pessoa, mas num corpo submisso, no caso da escola, às atividades intelectuais. Não é preciso lembrar aqui a situação da educação física referente ao horário escolar e aos espaços físicos da escola. Sem falar de uma certa distância do corpo docente.

A partir do imaginário existencial, com a Ressurreição do corpo, nas palavras de Roy Porter, certamente, estão abertas imensas e variadas perspectivas de conteúdos e práticas para a educação física desenvolver. A fonte de inspiração, na minha ótica, deveria ou deve ser a vida. A vida presente no corpo vivente com nome e sobrenome. Corpo e movimento são a constituição da existência individuall e os fundamentos das relações sociais. O movimento, para Buytendijk, é sempre uma forma de conduta, por isso "o jogo humano aparece sempre como um modo específico de comportamento"24.

Para uma primeira compreensão possivel, talvez decisiva, da ação pedagógica da educação física, os escritos de Humerto Maturana oferecem subsídios valiosos. Evidente, para quem adota o paradigma pedagógico da vida. Tudo pode começar pela afirmação de Maturana: "Nós, seres vivos, somos sistemas determinados em

${ }^{24}$ Buytendijk, , F.J.J. O jogo humano. In Nova Atropologia. Vol. 4, p. 63-87. São Paulo: EDUSP.1977. 
nossa estrutura"25. O que quer dizer que nesta estrutura estão inscritos nossas possibilidades e nossos limites. Somos o que está determinado pela estrutura. Não há o que reclamar. Neste sentido lembro Baudrillard ao referir-se à vida e à morte. Diz ele, "o direito à vida emociona até que se chega ao direito à morte". "Acontece, (acrescenta ele) que morrer - tanto quanto viver - é um destino, uma fatalidade (feliz ou infeliz), não é um direito"26.

Portanto, as possibilidades e limites, que todo ser vivo herda, são uma determinação, um destino. A tarefa é assumir essa herança genética, segundo a mesma situação do ser humano, referida por Heidegger, ao ver-se lançado no mundo sem ser consultado. A solução é assumir-se ou não. Propor-se uma existência autêntica ou alienada.

O que diferência Heideger e Maturana é o fundamento de raciocínio. O primeiro é filósofo, o segundo é biólogo. Entretanto, ambos chegam à mesma conclusão.

Maturana apresenta a base de seu projeto pedagógico colocando como ponto de partida o seguinte mandamento: "Vivamos nosso educar de modo que a criança aprenda a aceitar-se e respeitar-se em seu ser, porque assim aprenderá a aceitar e respeitar os outros. (...) E se a criança não pode aceitar-se e respeitar-se não pode aceitar e respeitar o outro"27.

Gerda Verden-Zöller, coautora de vários trabalhos com Maturana, de alguma maneira, situa as teses da educação biológica de Maturana no contexto da educação. Recorro a algumas cittações de seu trabalho porque são extremamente claras e diretas:

1. "A rigor, somos filhos do amor, e a biologia de nossas corporeidades, assim como a de nosso desenvolvimento infantil, pertence à biologia do amor"28.

\footnotetext{
${ }^{25}$ Maturana, Humberto. Emoções e Linguagem na Educação e na Política. Belo Horizonte: Editora UFMG, 2009. P. 27.

${ }^{26}$ Baudrillard, Jean. A Transparência do Mal. Campinas SP: Papirus, 1992. P.94.

${ }^{27}$ Maturana, H. Op. Cit. P.30.

${ }^{28}$ Verden-Zöller, Gerda. O Brincar na Relação Materno Infantil - Fundamentos biológicos da consciência de si mesmo e da Consciência Social. In. Maturana, H. e Verden-Zöller, G. Amar e Brincar - Fundamentos Esquecidos do Humano. São Paulo: Palas Athena, 2004. P. 135
} 
2. "Os ritmos corporais, e o fluxo das configurações de coordenações sensomotoras, no estreito contato corporal que acontece entre mãe e filho, são a base da qual surge a consciência humana"29.

3. "É só quando ela (criança) está operacionalmente consciente dessa corporeidade - conhece de modo operacional sua cabeça, pés, braços, mãos, ventre, costas - que pode vivê-la como padrão de orientação (o esquema corporal humano) com o qual constitui e organiza seu entorno e nele se orienta" 30 .

Seja qual for a situação da Educação Física e de seus profissionais, há uma perspectiva disponível presente na Teoria do Ensino do Movimento Humano de Peter Heinj, com o complemento da ideia de "se-movimentar" de Tamboer e Trebels. Acredito que seja legítimo acrescentar, a essa perspectiva, a tese da "Aprendência" exposta no livro, Reinventar o Ofício de Aprender, de Hélène Trocmé Faber ${ }^{31}$.

\subsection{Educação Física e Atividades Esportivas}

A segunda área da educação física é constituida por uma vasta paisagem formada pela variedade de atividades esportivas. Fica difícil, nos limites de meu projeto, selecionar alguns pontos mais significativos, já que são muitos e complexos. Seguem algumas opções:

\section{Ingresso do esporte na educação física.}

É frequente afirmar que o esporte entrou na educação física para preencher seu vazio programático. Tal afirmativa dá a entender que a educação física não tinha conteúdo programático e que o esporte era totalmente ausente da educação física. Paulo Ghirardelli Jr. publicou um folhetim sobre a questão dos conteúdos, no qual faz três distinções: 1. Esportes que nasceram no interior da educação física. Dá como exemplo o basquetebol. 2. Esportes que pertenciam a um movimento cultural específico. Exemplos, capoeira e judô. 3. Com o surgimento do mercado capitalista moderno a educação física teria sido subsjugada pelo desporto de performance ${ }^{32}$.

\footnotetext{
${ }^{29}$ Verden-Zöller, G. Op, Cit. P. 150.

${ }^{30}$ Idem. P. 159.

${ }^{31}$ Trocmé-Fabre, Hélène. Reinventar o Ofício de Aprender. São Paulo: Triom, 2010

${ }^{32}$ Ghirarddelli, Paulo, Jr. Educação Física e Pedagogia: a Questão dos Conteúdos. UFSM. 1990. P. 6
} 
É preciso, também, ressaltar que as construções foram desenhadas para os esportes. Um amplo estádio, ainda incompleto, e piscinas. A parte didática foi acomodada sob as arquibancadas.

\section{Conceito de Esporte.}

Pretender estabelecer um conceito único de esporte significa aventurar-se num labirinto sem o fio de Teseu ou de Ariadne. Em 1985, O Ministério da Educação, através da Secretaria de Educação Física e Desporto, elaborou um documento onde, além de tentar conceituar o desporto, faz uma série de distinções e classificações. No meu entender, faltou clareza de critérios.

\section{O esporte moderno}

Certamente, o que está, hoje, no centro das atenções é o esporte moderno, geralmente, definido como esporte de performance ou de (alto) redimento $O$ importante, sem negar a questão do rendimento, o esporte moderno caracterizado pela sua estrutura científica e técnica em função do resultado.

O princípio da competição fornece o combustível indispensável para energizar o atleta. Assim, o esporte performace é apresentado como esporte-espetáculo. Essa idéia de espetáculo, gira em torno da competição vitoriosa. E no esporte competitivo, "se ganha com o fracasso do outro"33. Há ganhador(es) triunfante(s) e perdedor(es) humilhado(s). No outro caso, o esporte de espetáculo seria uma apresentação artística, de arte, de beleza, de alegria que concluiria com o momento fulgurante, isto é, a apoteose.

Por fim, uma pergunta: A educação física assumiu o esporte moderno ou, ao contrário, o esporte moderno submeteu a educação física?

\section{Esporte, violência controlada}

Um dos componenetes presentes no esporte moderno seria, segundo Norbert Elias, o controle da violência. Como alguns esportes tiveram inspiração nos

${ }^{33}$ Maturana, H. Op. Cit. P. 21. 
enfretamentos belicosos, hoje, eles seriam, de certa maneira, a prática da violência autorizada. Os esportes de massa seriam uma válvula de escape de tensões sociais. Entretanto, com a previsão de limitar a violência atraves de regras que os atletas devem obedecer e de controle sobre as torcidas organizadas ${ }^{34}$.

A violência como componente essencial de certas lutas, classificadas como esporte, levanta uma dúvida sobre os critérios de esportividade. Por exemplo, as lutas de Boxe, MMA ou UFC, no meu entender, verdadeiros pugilatos para não dizer crimiosos. Cenas que, se acontecem foram dos ringues, são tidas como impróprias para serem apresentadas em programas de televisão. Mas como são esportes, ficam liberadas. Rinhas de galos são proibidas, mas é permitido colocar duas pessoas num ringue para se soquearem ferozmente até sangrar, diante de uma platéia delirante e sob o comando de um juiz.

E a educação física tem alguma responsabilidade sobre esses fenômenos crueis, chamados de esportes? Algum deles está no currículo ou nas academias comadadas por profissionais da educação física?

A ética e a bioética oferecem bons argumentos para responder.

\section{Esporte, corpo e movimento.}

Esta é a questão fundamental que coloca em lados opostos a educação física: ação pedagógica - esporte moderno ou de rendimento. A solução desta questão está na resposta dessa dupla pergunta: a educação física determina o esporte ou o esporte determina a educação física? A resposta pode ser encontrada nas práticas diárias.

As mesmas perguntas podem ser feitas em relação ao corpo e ao movimento. O corpo e o movimento são determinados pela dinâmica da Vida, como seria no "se-movimentar" (sic Bewegen) ou são determinados pela ciência e técnicas de cada modalidade esportiva?

${ }^{34}$ Elias, Norbert, Dunning, Eric. Sport et civilisation - la violence maîtrisée. Paris: Fauard. 1994. 
Vou me valer de alguns pensadores que respondem criticamente a esse questionamento. Aqui, observo, entra em ação a minha escolha ideológica.

Começo citando Baudrillard: "Praticar Jogging não é correr, é fazer o corpo correr. É um jogo que se baseia na performance informal do corpo, jogo que procura simultaneamente esgotar e destruir o corpo". (...) "O corpo hipnotizase no seu desempenho e corre por si só, como se o sujeito estivesse ausente, como máquina sonâmbula e celibatária"35. Ou, ainda, correr 100 metros em dez segundos corresponde melhor ao corpo do que caminhar tranquilamente nas trilhas em meio à natureza?

Jean-Marie Brohm é um sociólogo que pesquisou amplamente os efeitos dos esportes modernos sobre os indivíduos e sobre as atividades humanas em geral. Da atividade educacional, passando pela economia, até a política. Resumidamente, pode-se dizer que sua tese central se baseia numa dupla falsa ilusão. A proclamada libertação do corpo se transformou em nova servidão. A suposta sublimação das manifestações esportivas se transformou numa dessublimação ${ }^{36}$.

Em contra partida, Ginette Berthaud apresenta alguns aspectos positivos como formação do caráter, o recrutamento de futuros campeões e preparação pela competitividade para a nova sociedade ${ }^{37}$.

\subsection{Educação Física e saúde.}

A nova área de atuação da educação física, e com todo direito, é a da saúde. Talvez, a saúde seja, ao lado da pedagogia, o conteúdo programático mais valioso da educação física. Óbvio se a educação física tiver como centro de sua atuação a corpoeidade humana, em sua constituição como corpo vivente, e suas manifestações no "se-movimentar".

\footnotetext{
${ }^{35}$ Baudrillard, Jean. A Transparência do Mal - Ensaiso sobre os Fenômenos Extremos. Campinas SP: Papirus, 1992. P. 54. Ver também do mesmo autor, América. Barcelona: Anagrama, 1987. P. 57 ss.

${ }^{36}$ Brohm, Jean-Marie. Sociologie Polítique du Sport. Paris: Delarge, éditeur. 1976. Também, Bertthaud, Ginette. Educacions deportiva y deporte educativo. In Deporte, cultura y répression. Barcelona:Editorial Gilli, 1978. P. 97-127.

${ }^{37}$ Gantheret, François. Psicoanálisis institucional de la educación física y de los deportes. Idem. P. 86 .
} 
A educação física assumida ao pé da letra seria uma medicina preventiva. Pelo simples fato de que está encarregada de acompanhar o desenvolvimento da corporeidade humana, com maior razão se o corpo for assumido como o modo de ser do ser humano. Educar o corpo não significa discipliná-lo, mas reconhecer sua sabedoria. Henri Atlan, em seu livro Centelhas de Acaso, escreveu "Ninguém sabe o que o corpo pode (...) e não sabemos como sabemos, enquanto não conhecermos o conhecimento que o nosso corpo tem"38. Além disso, avisa Merleau-Ponty, o corpo é falante. Ele emite mensagens e sinais constantemente ${ }^{39}$. A melhor maneira de conhecer o corpo é viver o corpo.

A educação física, sen dúvida nenhuma, tem muito a oferecer para as ciências da saúde. A educação física poderia assumir a responsabilidade de praticar a medicina preventiva pelo fato de acompanhar o desenvolvimento corporal. Da mesma maneira que a educação intelectual acomapnha o desenvolvimento da inteligência. O corpo é um organismo vivente, não uma máquina. Ou, até poderia ser máquina, mas uma máquina viva. Antes de precisar remédios externos, ela tem seus recursos internos.

Uma grande bandeira da educação física para fazer tremular no campo da saúde, é o badalado mantra: o esporte é saúde. Pode ser e pode não ser. Se considerarmos os benefícios que traz para quem o pratica respeitando o corpo, é saúde. Se olharmos para os praticantes que violentam o corpo, como observou Baudrillard, o esporte não é saúde. E mais, se prestarmos atenção sobre os departamentos médicos dos clubes, fica complicando defender que o esporte é sempre saúde. E as lesões, e as agresões, e os massacres do boxe, MMA, UFC como situar no perfil de "esporte é saúde"? O desenvolvimento da medicina esportica seria a grande justificativa.

\footnotetext{
${ }^{38}$ Atlan, Henri. Les Éticelles de Hasard. Paris: Éditions du Seuil, 1999. P. 93

${ }^{39}$ Merleau-Ponty, M. Op. Cit p. 202-230
} 


\section{Referências}

ATLAN, Henri. Les Éticelles de Hasard. Paris: Éditions du Seuil, 1999.

BAUDRILLARD, Jean. A Transparência do Mal - Ensaiso sobre os Fenômenos Extremos. Campinas SP: Papirus, 1992

BROHM, Jean-Marie. Sociologie Polítique du Sport. Paris: Delarge éditeur, 1976.

CAPRA, Fritjof. O Ponto de Mutação. São Paulo: Cultrix, 1982.

CASSIRER, Ernest. Ls philosofie des formes symboliques. Paris: Les Ed.Minuit, 1953.

CHARDIN, Teilhard de. O Fenômeno Humano. São Paulo: Cultrix, 1955.

ELIAS, Norbert, DUNNING, Eric. Sport et civilisation - la violence maîtrisée. Paris: Fauard. 1994.

FOUREZ, Gérard. As Construções das Ciências - Introdulçao à Filosofia e à Ética das Ciências. São Paulo: UNESP, 1995.

HEIDEGGER, Martin. Was heisst Denken. Ed.Vit. Klostermann. 1954. Trad. Francesa, BECKER, Aloys e GRANEL, Gérard. Qu'Appelle-t-on Penser? Paris: PUF, 1967.

KOYRÉ, Alexandre. Du monde clos à l'univers infini. Paris: idées Gallimard. 1973

KUHN, Thomas. A Estrutura das Revoluções Científicas. São Paulo; Ed. Perspectiva, 1987.

LATOUR, Bruno e WOLGAR, Steve. A Vida de Laboratório - A produção dos fatos científicos. Rio de Janeiro: Relume Dumará, 1997. 
MATURANA, H. e Verden-Zöller, G. Amar e Brincar - Fundamentos Esquecidos do Humano. São Paulo: Palas Athena, 2004.

MONOD, Jacques. O Acaso e a Necessidade. Petrópolis: Vozes, 1976.

RICOEUR. Paul. Les conflit des interprétations - essais d'herméneutique. Paris: Éditions du Seuil, 1969. P. 64.

THON, René. Aaventura cientifica sob risco de heresia. In PESSIA-PASTERNAK, Guitta. Do Caos à Inteligência Artificial. São Paulo: UNESP, 1991

VARELA, Francisco. Connaître - Les sciences cognitives tendances et perspectives. Paris: Seuil, 1988. 


\section{Exercises to Think the Game of Epistemes}

Abstract: This is an exercise in philosophical thinking about the game of epistemes in the construction of knowledge in and for the Physical Education. The main objective, however, is to identify possible motivations, interests and needs that led men to develop and organize the capacity of thinking and thus, in the case, build knowledge. For the Physical education it is analyzed like this, "roads and detours that tensioning epistemes".

Keywords: Game. Episteme. Physical Education.

\section{Ejercicios para Pensar el Juego de Epistemes}

Resumen: Este es un ejercicio de lo pensamiento filosófico sobre el juego de epistemes en la construcción del conocimiento y de la Educación Física. El objetivo principal es, sin embargo, identificar posibles motivaciones, intereses y necesidades que llevaron a los hombres a desarrollar y organizar la capacidad de pensar y, por lo tanto, en el caso, construir el conocimiento. Para el análisis de educación física es, pues, "los caminos y desvíos que epistemes perspectiva".

Palabras Claves: Juego. Epistemes. Educación Física. 